\title{
Performance of Shrouded Pin-Fin Heat Sinks for Electronic Cooling
}

\author{
W. A. Khan, ${ }^{*}$ J. R. Culham, ${ }^{\dagger}$ and M. M. Yovanovich ${ }^{\ddagger}$ \\ University of Waterloo, Waterloo, Ontario N2L 3G1, Canada
}

\begin{abstract}
The objective of this study is to analyze the performance of a cylindrical pin-fin heat sink in laminar forced convection. The mathematical models are presented for predicting thermal and hydraulic resistances for both in-line and staggered arrangements. Analytical/empirical correlations of friction and heat transfer coefficients are used in the analysis. The analyses are performed by using parametric variation of resistances. The effects of thermal joint, spreading, and contact resistances as well as the thermal conductivity on the overall thermal performance are examined. For a given size and heat load, it is observed that the overall performance of a pin-fin heat sink depends on a number of parameters including the dimensions of the pin-fins, pin density, longitudinal and transverse spacings, interface material, location and size of heat sources, method of manufacturing, type of heat-sink material, approach velocity, and arrangement of pins. It is also observed that the thermal resistance decreases whereas pressure drop increases with an increase in approach velocity, pin diameter, and pin density.
\end{abstract}

\section{Nomenclature}

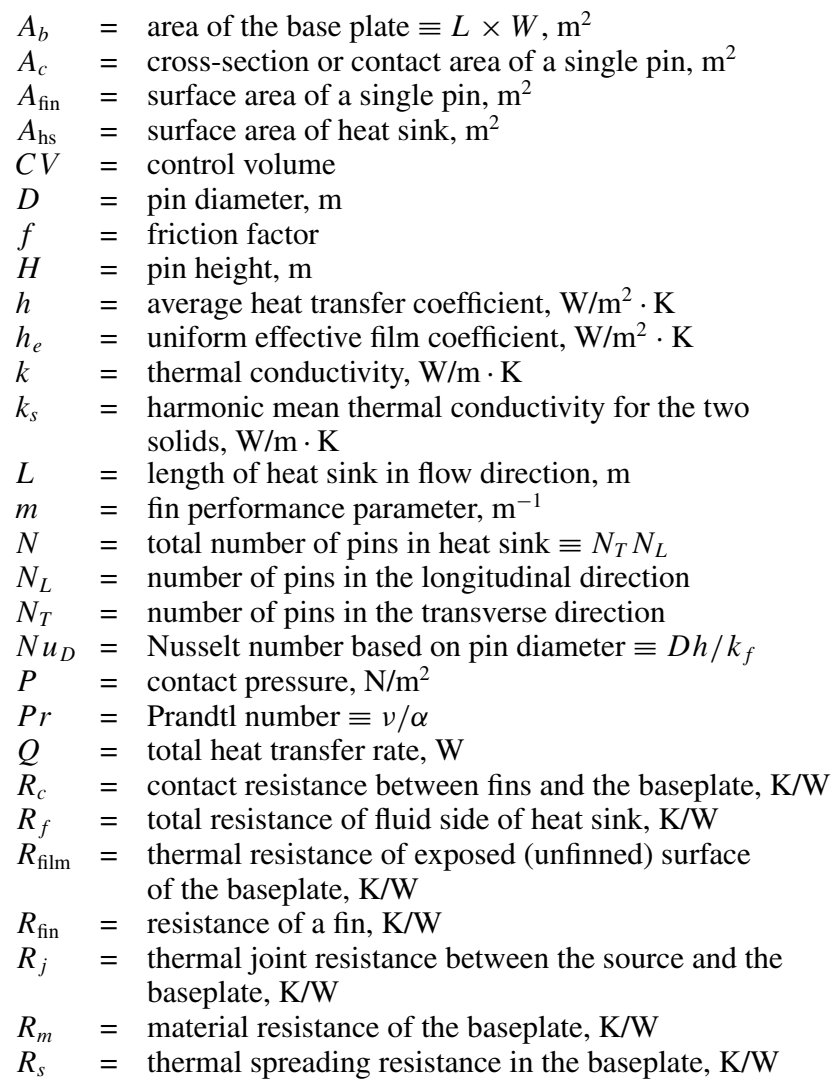

Received 16 May 2005; presented as Paper 2005-5071 at the AIAA 38th Thermophysics Conference, Toronto, Canada, 6-9 June 2005; revision received 20 July 2005; accepted for publication 28 July 2005. Copyright (C) 2005 by the American Institute of Aeronautics and Astronautics, Inc. All rights reserved. Copies of this paper may be made for personal or internal use, on condition that the copier pay the $\$ 10.00$ per-copy fee to the Copyright Clearance Center, Inc., 222 Rosewood Drive, Danvers, MA 01923; include the code 0887-8722/06 \$10.00 in correspondence with the CCC.

*Postdoctoral Fellow, Department of Mechanical Engineering. Member AIAA.

${ }^{\dagger}$ Associate Professor and Director, Microelectronics Heat Transfer Laboratory, Department of Mechanical Engineering.

${ }^{\ddagger}$ Distinguished Professor Emeritus, Department of Mechanical Engineering. Fellow AIAA.

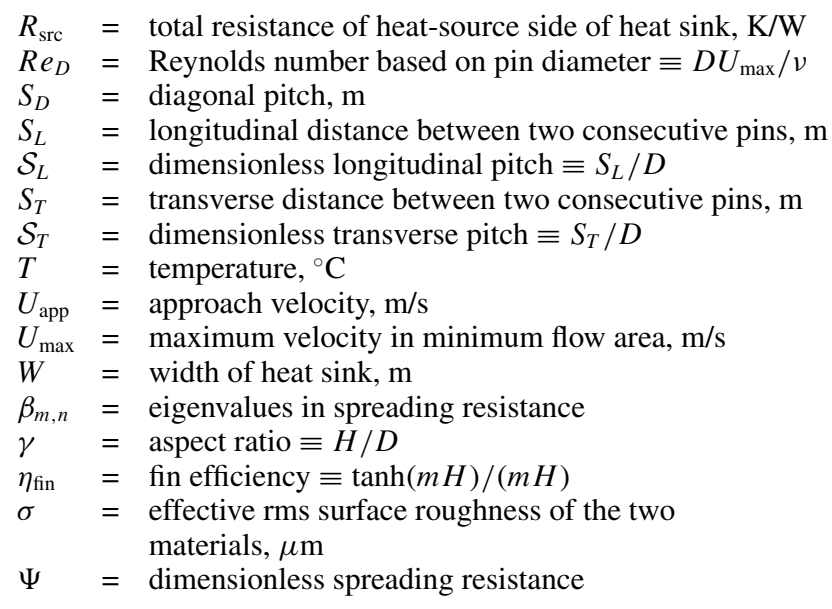

Subscripts

$a=$ ambient

$b \quad=\quad$ base plate or unfinned surface of baseplate

$c \quad=$ contact

$f \quad=$ fluid

fin $=$ single fin

fins $=$ all fins with exposed baseplate area

$h s \quad=$ heat sink

$m \quad=$ bulk material

$T=$ thermal

$w \quad=$ wall

\section{Introduction}

$\mathbf{T}$ HE continuing increase of power densities in microelectronics and the simultaneous drive to reduce the size and weight of electronic products have led to an increased importance of thermal management issues in this industry. The temperature at the junction of an electronics package (chip temperature) has become the limiting factor determining the lifetime of the package. The most common method for cooling packages is the use of pin-fin heat sinks. These heat sinks provide a large surface area for the dissipation of heat and effectively reduce the thermal resistance of the package. They often take less space and contribute less to the weight and cost of the product than other options. For these reasons, they are widely used in applications where heat loads are substantial and/or space is limited. They are also useful in situations where the direction of the approaching flow is unknown or may change. 
They offer a low-cost, convenient method for lowering the thermal resistance and in turn maintaining junction temperature at a safe level for long-term, reliable operation. The overall performance of a pin-fin heat sink depends on a number of parameters including the dimensions of the baseplate and pin-fins, pin density, longitudinal and transverse spacings, thermal conductivity of the material, approach velocity, and arrangement of pins. These parameters make the parametric analysis of a heat sink very difficult.

A careful review of the literature reveals that no theoretical study exists that compares the overall performance of pin-fin heat sinks based on the thermal and the hydraulic resistance. However, few experimental/numerical studies exist related to the thermal or hydraulic performance of fully shrouded pin-fin heat sinks.

Wirtz et al. ${ }^{1}$ reported experimental results on the thermal performance of model pin-fin fan-sink assemblies. They used cylindrical, square, and diamond-shaped cross-sectional pin-fins and found that cylindrical pin-fins give the best overall fan-sink performance. Furthermore, the overall heat-sink thermal resistance decreases with an increase in either pressure rise or fan power and fin height.

Jonsson and Bjorn ${ }^{2}$ performed experiments to compare the thermal performance of heat sinks with different fin designs including straight fins and pin fins with circular, quadratic, and elliptical cross sections. They evaluated the thermal performance by comparing the thermal resistance of the heat sinks at equal average velocity and equal pressure drop. They recommended elliptical pin-fin heat sinks at high velocities and circular pin-fin heat sinks at midrange velocities.

Babus'Haq et al. ${ }^{3}$ investigated experimentally the thermal performance of a shrouded vertical Duralumin pin-fin assembly in in-line and staggered configurations. They found that under similar flow conditions and for an equal number of pin-fins, the staggered configuration yields a higher steady-state rate of heat transfer than the in-line configuration. They studied the effect of changing the thermal conductivity of the pin-fin material and found that the optimal separation between the pin-fins in the streamwise direction increased with the thermal conductivity of the pin-fin material, whereas the optimal separations in the spanwise direction remained invariant.

Azar and Mandrone ${ }^{4}$ investigated the effect of pin-fin density on thermal performance of unshrouded pin-fin heat sinks. They found an optimal number of pin fins beyond which thermal resistance actually increased. They also found that thermal resistance was a function of the approach velocity and the governing flow pattern. Furthermore, pin-fin heat sinks with a small number of pins had the best performance at low and moderate forced-convection cooling.

Minakami and Iwasaki ${ }^{5}$ conducted experiments to investigate the pressure-loss characteristics and heat transfer performance of pin-fin heat sinks exposed to air flow in a cross-flow direction, varying the pin pitch as a parameter. They found that as the longitudinal pitch increased, the heat transfer coefficient increased and the pressure loss also increased. Furthermore, as the transverse pitch decreased, the heat transfer coefficient increased, but the pressure loss increased drastically compared to the $N u_{D}$.

The steady-state thermal and air-flow resistance performances of horizontally based pin-fin assemblies were investigated experimentally by Tahat et al. ${ }^{6}$ They studied the effects of varying geometrical configurations of the pin-fins and found the optimal pin-fin separation in both streamwise and spanwise directions to achieve maximum heat transfer rate.

Dvinsky et al. ${ }^{7}$ performed a numerical study of two square pin-fin heat sinks using the commercial CFD software Coolit ${ }^{\circledR}$. They found that the in-line design was thermally superior to the staggered design for all but the fully shrouded heat sinks. They also found that in a given geometry the nondimensional pressure drop over a heat sink was almost constant, which indicates small viscous drag.

Jung and Maveety ${ }^{8}$ performed numerical experiments to investigate the turbulent fluid flow and heat transfer from three pin-fin heatsink geometries over the $R e_{D}$ range from 7800 to 19,700 with air impingement cooling. They used a standard $\kappa-\epsilon$ turbulence model to predict the Reynolds stresses. They found that the maximum heat transfer dissipated from a heat sink was obtained under turbulentflow conditions.
You and Chang ${ }^{9}$ predicted numerically the forced convection heat transfer rate for a cooling fluid through a pin-fin porous channel. They found that the flow inside the pin-fin channel reaches the fully developed thermal state in the early downstream region.

\section{Analysis}

Two schematics of the pin-fin heat sinks used in this study are shown in Figs. 1 and 2. The dimensions of the baseplate are $W \times L \times t_{b}$, where $W$ is the width of the entrance, $L$ is the length measured in the downstream direction, and $t_{b}$ is the thickness of the base plate. Each pin fin has diameter $D$ and height $H$. The dimensionless longitudinal and transverse pitches are $\mathcal{S}_{L}=S_{L} / D$ and $\mathcal{S}_{T}=S_{T} / D$. The source of heat is applied to the bottom of the heat sink. The flow is assumed to be laminar, steady, and two dimensional. The approach velocity of the fluid is $U_{\text {app }}$, and the ambient temperature is $T_{a}$. The heat sink is fully shrouded; that is, there is no leakage of fluid from the top or sides. The wall temperature of the pin is $T_{w}\left(>T_{a}\right)$, and the baseplate temperature is $T_{b}$.

\section{A. Heat-Sink Thermal Resistance}

The thermal performance of a pin-fin heat sink depends upon the total thermal resistance of the heat sink from a heat source on one side and a fluid on the other side. This thermal resistance is defined as

$$
R_{\mathrm{hs}}=\theta_{s} / Q
$$

where $\theta_{s}=T_{s}-T_{a}$ (see Fig. 3). The total thermal resistance of the heat sink can also be written as the sum of the two main resistances, $R_{\text {src }}$ and $R_{f}$ :

$$
R_{\mathrm{hs}}=R_{\mathrm{src}}+R_{f}
$$

where

$$
R_{\mathrm{src}}=R_{j}+R_{s}+R_{m}
$$

and

$$
R_{f}=1 /\left[N /\left(R_{c}+R_{\mathrm{fin}}\right)+1 / R_{\mathrm{film}}\right]
$$

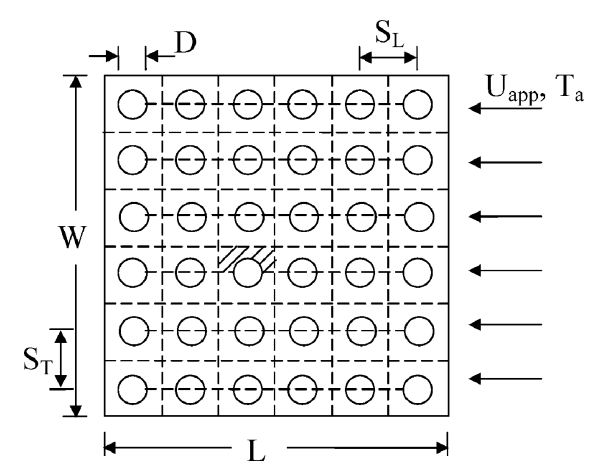

Fig. 1 Schematic of in-line pin-fin heat sinks.

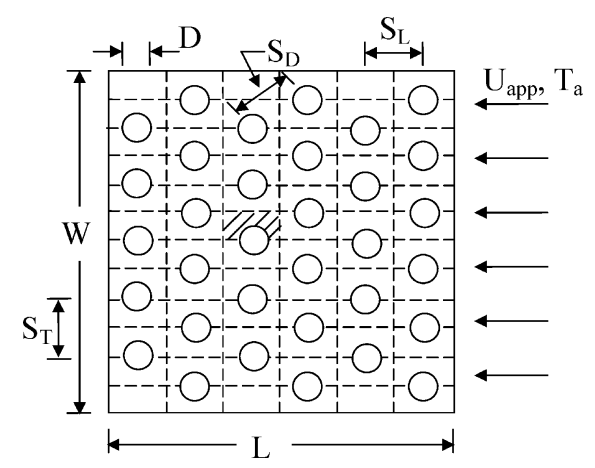

Fig. 2 Schematic of staggered pin-fin heat sinks. 


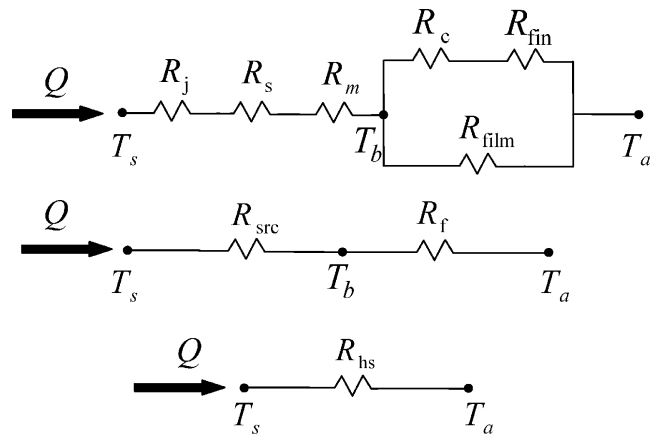

Fig. 3 Thermal resistance network for a heat sink.

Fig. 4 Interface between heat source and baseplate.

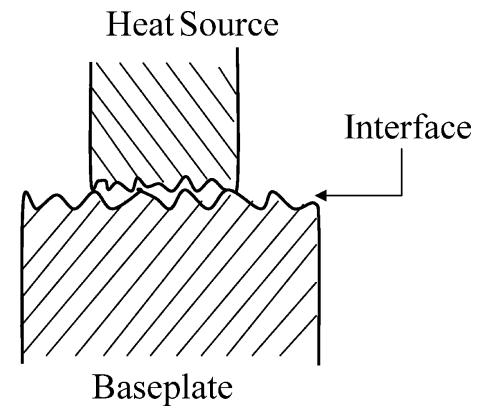

These resistances are shown in Fig. 3 and are discussed in detail.

\section{Thermal Joint Resistance $\mathrm{R}_{\mathrm{j}}$}

Because of surface irregularities at the interface between the heat source and the baseplate, only a fraction of the total apparent area is in contact (Fig. 4). As a result, a temperature drop occurs that depends on the thermal resistance of the contacting interface.

Thermal joint resistance at the interfaces is a function of several geometric, physical, and thermal parameters such as surface roughness and waviness; surface microhardness; thermal conductivity of the contacting solids; including layers, coatings, and films; properties of any interstitial materials; and the contact pressure. Interstitial substances, such as gases, greases, oils, liquids, and so forth, that completely fill the gaps formed between contacting asperities can perfectly wet interfacial surfaces, producing interfaces that have relatively high contact conductances. Thin conductive layers, in the range of $1-50 \mu \mathrm{m}$ in thickness, created when vapor is deposited on contacting surfaces, can decrease joint resistance by at least an order of magnitude.

As an alternative to deposited layers, interstitial metallic foils made of aluminum, copper, indium, lead, tin, and so forth can be placed between contacting rough surfaces to significantly decrease the joint resistance. Many researchers including Yovanovich, ${ }^{10,11}$ Savija et al., ${ }^{12}$ and Bahrami et al. ${ }^{13}$ have presented analytical and empirical models for calculating the thermal joint resistance under different conditions. Yovanovich ${ }^{10}$ established the following correlation for conforming rough surfaces when interstitial fluids such as grease and gases are present in the gap:

$$
R_{j}=\left\{\left[1.25 k_{s}(m / \sigma)\left(P / H_{c}\right)^{0.95}+k_{g} /(Y+M)\right] A_{a}\right\}^{-1}
$$

Yovanovich et al. ${ }^{14}$ used the aforementioned model to calculate the joint resistance at the interface formed by an aluminum 6063-T5 aluminum heat sink and an $\mathrm{Al}_{2} \mathrm{O}_{3}$ alumina package. The thermal conductivities of these materials are $201 \mathrm{~W} / \mathrm{m} \cdot \mathrm{K}$ and $20.9 \mathrm{~W} / \mathrm{m} \cdot \mathrm{K}$ respectively. The microhardness of the aluminum alloy $H_{c}=1094 \mathrm{MPa}$, surface roughness for flycut aluminum of $\sigma_{1}=0.4 \mu \mathrm{m}$, and a surface roughness for ground alumina of $\sigma_{2}=1.3 \mu \mathrm{m}$ were used to compute contact parameters. The specific thermal joint resistances are plotted for air $\left(k_{g}=0.026 \mathrm{~W} / \mathrm{m} \cdot \mathrm{K}\right)$ and grease $\left(k_{g}=0.2 \mathrm{~W} / \mathrm{m} \cdot \mathrm{K}\right)$ in Fig. 5 against the nominal contact pressure over the pressure range $0.007 \leq P(\mathrm{MPa}) \leq 0.35$.

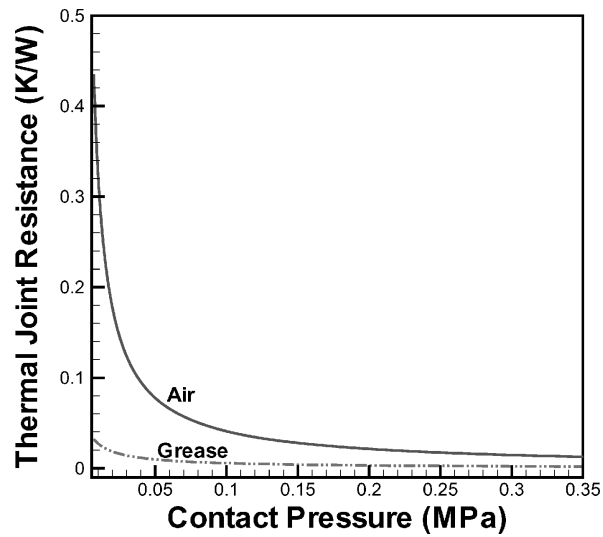

Fig. 5 Thermal joint resistance of aluminum heat sink, ceramic package.

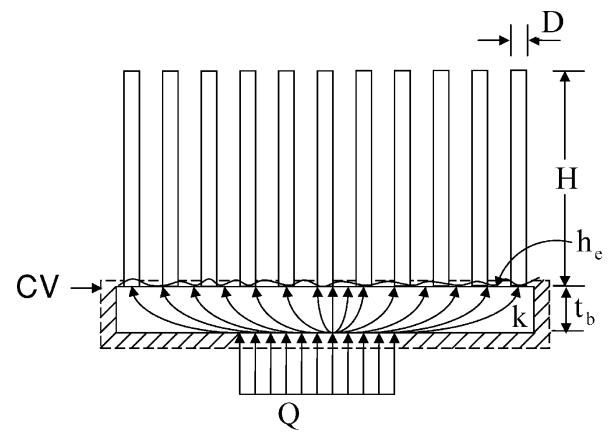

Fig. 6 Control volumes for energy balances.

For grease, the thermal joint resistance is much smaller than the bare interface with air. The calculated values of the contact resistance for grease are an order of magnitude smaller than the contact resistance of a bare joint. In this study $R_{j}=0.004 \mathrm{~K} / \mathrm{W}$ (at $0.15 \mathrm{MPa}$ contact pressure) is used for grease.

\section{Spreading Resistance $\mathrm{R}_{\mathrm{s}}$}

Thermal spreading resistance occurs when heat flow spreads from a surface-mounted heat source into a conducting solid (baseplate, in the case of a heat sink). Figure 6 shows a planar rectangular heat source situated on the bottom surface of the baseplate having thickness $t_{b}$ and thermal conductivity $k$. The baseplate is cooled along the top surface through a uniform effective film coefficient $h_{e}$, which can be determined by the energy balance in CV 1 (Fig. 6):

$$
Q=Q_{b}+Q_{\text {fins }}
$$

where

$$
\begin{gathered}
Q=h_{e} A \theta_{b} \\
Q_{b}=(h A)_{b} \theta_{b} \\
Q_{\text {fins }}=(h \eta A)_{\text {fins }} \theta_{b}
\end{gathered}
$$

with $\theta_{b}=\bar{T}_{b}-T_{a}$, and

$$
A=L W, \quad A_{b}=L W-N(\pi / 4) D^{2}, \quad A_{\text {fins }}=N \pi D H
$$

The efficiency of the fin $\eta_{\text {fin }}$ with constant heat transfer coefficient and an insulated tip is given by

$$
\eta_{\text {fin }}=\frac{\tanh (m H)}{m H}
$$

with the fin parameter $m=\sqrt{ }\left(4 h_{\text {fin }} / k D\right)$. 
Khan ${ }^{15}$ determined analytically the heat transfer coefficients for the baseplate and the fins, given by

$$
\begin{gathered}
h_{b}=0.75\left[\left(k_{f} / D\right) / \sqrt{N_{L} S_{L}}\right] \operatorname{Re}_{D}^{\frac{1}{2}} \operatorname{Pr}^{\frac{1}{3}} \\
h_{\text {fin }}=C_{1}\left(k_{f} / D\right) \operatorname{Re}_{D}^{\frac{1}{2}} \operatorname{Pr}^{\frac{1}{3}}
\end{gathered}
$$

where $R e_{D}$ is the Reynolds number based on the pin diameter $D$ and the mean velocity in the minimum free cross section between two rows, $U_{\max }$, for both types of arrangements and is defined as

$$
R e_{D}=D U_{\max } / v
$$

with

$$
U_{\max }=\max \left\{\left[\mathcal{S}_{T} /\left(\mathcal{S}_{T}-1\right)\right] U_{\text {app }},\left[\mathcal{S}_{T} /\left(\mathcal{S}_{D}-1\right)\right] U_{\text {app }}\right\}
$$

where $U_{\text {app }}$ is the approach velocity, $\mathcal{S}_{L}$ and $\mathcal{S}_{T}$ are the dimensionless longitudinal and transverse pitches, and $\mathcal{S}_{D}=\sqrt{ }\left[\mathcal{S}_{L}^{2}+\left(\mathcal{S}_{T} / 2\right)^{2}\right]$ is the dimensionless diagonal pitch in case of a staggered arrangement. The constant $C_{1}$ in Eq. (12) depends on the geometry of the heat sink and is given by

$C_{1}=$

$$
\begin{cases}{\left[0.2+\exp \left(-0.55 \mathcal{S}_{L}\right)\right] \mathcal{S}_{T}^{0.285} \mathcal{S}_{L}^{0.212}} & \text { In-line arrangement } \\ \frac{0.61 \mathcal{S}_{T}^{0.091} \mathcal{S}_{L}^{0.053}}{\left[1-2 \exp \left(-1.09 \mathcal{S}_{L}\right)\right]} & \text { Staggered arrangement }\end{cases}
$$

Combining Eqs. (7-12), Eq. (6) can be solved for the uniform effective film coefficient $h_{e}$ :

$$
h_{e}=\frac{k_{f} / D}{\mathcal{S}_{T} \mathcal{S}_{L}}\left\{\pi C_{1} \gamma \eta_{\text {fin }}+\frac{0.75\left(\mathcal{S}_{T} \mathcal{S}_{L}-\pi\right)}{\sqrt{N_{L} \mathcal{S}_{L}}}\right\} \cdot \operatorname{Re}_{D}^{\frac{1}{2}} \operatorname{Pr}^{\frac{1}{3}}
$$

The heat-source area is rectangular and has dimensions $l \times w$. The lateral boundaries of the baseplate are adiabatic. Many models exist for spreading resistance subject to various imposed boundary conditions. In this study, only two models are employed to determine the spreading resistance. The first full model is given by Yovanovich et al. ${ }^{16}$ :

$$
\begin{aligned}
R_{s}= & \frac{8}{L W k}\left[\frac{1}{l^{2}} \sum_{m=1}^{\infty} \frac{\sin ^{2}(l \delta / 2)}{\delta^{3}} \phi_{m}(\delta)+\frac{1}{w^{2}} \sum_{n=1}^{\infty} \frac{\sin ^{2}(w \lambda / 2)}{\lambda^{3}} \phi_{n}(\lambda)\right. \\
& \left.+\frac{8}{l^{2} w^{2}} \cdot \sum_{m=1}^{\infty} \sum_{n=1}^{\infty} \frac{\sin ^{2}(l \delta / 2) \sin ^{2}(w \lambda / 2)}{\delta^{2} \lambda^{2} \beta} \phi_{m, n}(\beta)\right]
\end{aligned}
$$

where the eigenvalues $\delta_{m}, \lambda_{n}$, and $\beta_{m, n}$ are given by

$$
\delta_{m}=2 m \pi / L, \quad \lambda_{n}=2 n \pi / W, \quad \beta_{m, n}=\sqrt{\delta_{m}^{2}+\lambda_{n}^{2}}
$$

The contributions of the baseplate thickness $t_{b}$, thermal conductivity $k$, and the uniform conductance $h_{e}$ to the spreading resistance are determined by means of the general expression

$$
\phi(\zeta)=\frac{\left(e^{2 \zeta t_{b}}+1\right) \zeta+\left(1-e^{2 \zeta t_{b}}\right) h_{e} / k}{\left(e^{2 \zeta t_{b}}-1\right) \zeta+\left(1+e^{2 \zeta t_{b}}\right) h_{e} / k}
$$

In all summations $\phi(\zeta)$ is evaluated in each series using $\zeta=\delta_{m}, \lambda_{n}$, and $\beta_{m, n}$ as defined previously.

The second model, which is an approximate model for calculating spreading resistance, is given by Song et al. ${ }^{17}$ It is the solution to a single circular source of uniform flux on a circular substrate of uniform thickness. However, modifications can be made for a rectangular heat source and heat sinks. According to this model,

$$
R_{s}=\Psi / \sqrt{\pi} k a
$$

where $\Psi$ is the dimensionless spreading resistance and includes the bulk material resistance $R_{m}$, which is normally estimated as $t_{b} / k A_{b}$. This dimensionless spreading resistance is given by

$$
\Psi=\epsilon \tau / \sqrt{\pi}+\frac{1}{2}(1-\epsilon)^{\frac{3}{2}} \phi_{c}
$$

where

$$
\phi_{c}=\frac{\tanh \left(\lambda_{c} \tau\right)+\lambda_{c} / B i}{1+\left(\lambda_{c} / B i\right) \tanh \left(\lambda_{c} \tau\right)}
$$

with

$$
\begin{array}{r}
\lambda_{c}=\pi+\frac{1}{\sqrt{\pi} \epsilon}, \quad a=\sqrt{\frac{A_{s}}{\pi}}, \quad b=\sqrt{\frac{A_{b}}{\pi}} \\
\epsilon=\frac{a}{b}, \quad \tau=\frac{t_{b}}{b}, \quad B i=\frac{h_{e} A_{\mathrm{fin}} \eta_{\mathrm{fin}}}{\pi b k}
\end{array}
$$

3. Material Resistance $\mathrm{R}_{\mathrm{m}}$

This resistance depends upon the thickness $t_{b}$, thermal conductivity, and the area of the baseplate $A$ and can be written as

$$
R_{m}=t_{b} / k A_{b}
$$

4. Contact Resistance $\mathrm{R}_{\mathrm{c}}$

When the pin-fins are machined as an integral part of the baseplate, there is no contact resistance at their base. However, when pin-fins are manufactured separately and are attached to the baseplate by a metallurgical or adhesive joint or are forced into slots machined on the baseplate, thermal contact resistance $R_{c}$ can adversely influence the thermal performance of the heat sink. This resistance depends upon the attachment methods involving an adhesive or bonding agent as well as the contact area of the fins $A_{c}$ with the baseplate and is written as

$$
R_{c}=1 /(h A)_{c}
$$

where $A_{c}=N\left(\pi D^{2} / 4\right)$ is the total contact area of the fins and $h_{c}$ is the thermal contact conductance that ranges typically from $10^{4}$ (metallurgical joint) to $10^{10}$ (perfect joint).

\section{Fin Resistance $\mathrm{R}_{\text {fin }}$}

The thermal resistance of the fin $R_{\text {fin }}$ is a function of fin efficiency $\eta_{\text {fin }}$, the surface area of the fin $A_{\text {fin }}$, and the convection heat transfer coefficient $h_{\text {fin }}$. Conduction and convection heat transfer are taken into consideration when analyzing the thermal contact resistance of the fin. Heat is carried out through the fin by conduction and dissipated to the surrounding ambient air by convection. The overall resistance of the fin can be written as

$$
R_{\text {fin }}=1 /(h A \eta)_{\text {fin }}
$$

where $\eta_{\text {fin }}$ and $h_{\text {fin }}$ can be determined from Eqs. (10) and (12) respectively.

\section{Film Resistance $\mathrm{R}_{\text {film }}$}

Heat convected from the exposed (unfinned) surface of the baseplate is given by Eq. (8), where the heat transfer coefficient for the exposed surface of the baseplate $h_{b}$ can be determined from Eq. (11). Recalling the definition of the thermal resistance, Eq. (1) can be used to define an expression for the thermal resistance of the exposed surface of the baseplate; that is,

$$
R_{\mathrm{film}}=\theta_{b} / Q_{b}=1 / h_{b}\left[L W-N\left(\pi D^{2} / 4\right)\right]
$$




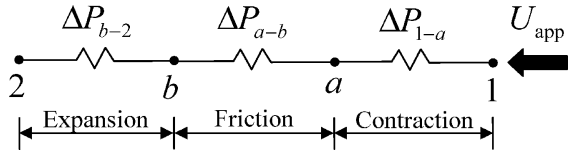

Fig. 7 Hydraulic resistance network for heat sink.

\section{B. Total Heat-Sink Pressure Drop}

In heat sinks, the pressure drop is important because of its relationship to the power required to move the fluid across the fin arrays. This pressure drop across the heat sink is also known as the hydraulic resistance of the system. It affects the overall performance of the heat sink. Higher hydraulic resistance causes less airflow through the heat-sink channel, attaining a lower convection heat transfer rate between the fins and the surrounding air and increasing fin thermal resistance. The actual volumetric flow rate can be found from the fan performance curve with a given total heat-sink pressure drop. This point along the fan curve is called the system operating point. For a heat sink, the total pressure drop should also include the abrupt contraction and the abrupt expansion effects of the heat sink (Fig. 7) and is written as

$$
\Delta P_{\mathrm{tot}}=\Delta P_{1-a}+\Delta P_{a-b}+\Delta P_{b-2}
$$

where $\Delta P_{1-a}$ is the pressure drop resulting from the irreversible free expansion that always follows the abrupt contraction, $\Delta P_{a-b}$ is the pressure loss resulting from core friction, and $\Delta P_{b-2}$ is the pressure loss associated with the irreversible free expansion and momentum changes following an abrupt expansion. These pressure drops can be written as

$$
\begin{gathered}
\Delta P_{1-a}=K_{c} \cdot\left(\rho U_{\max }^{2} / 2\right) \\
\Delta P_{b-2}=K_{e} \cdot\left(\rho U_{\max }^{2} / 2\right) \\
\Delta P_{a-b}=f N_{L} \cdot\left(\rho U_{\max }^{2} / 2\right)
\end{gathered}
$$

where $K_{c}$ and $K_{e}$ are the abrupt contraction and abrupt expansion coefficients respectively, $f$ is the friction factor, and $N_{L}$ is the number of pins in the longitudinal direction. The coefficients of abrupt contraction and expansion have been established graphically by Kays ${ }^{18}$ for a number of geometries. The following correlations are derived from those graphs:

$$
\begin{gathered}
K_{c}=-0.0311 \sigma^{2}-0.3722 \sigma+1.0676 \\
K_{e}=0.9301 \sigma^{2}-2.5746 \sigma+0.973
\end{gathered}
$$

with

$$
\sigma=\left(\mathcal{S}_{T}-1\right) / \mathcal{S}_{T}
$$

Žukauskas and Ulinskas ${ }^{19}$ collected data, from a variety of sources, about friction factors for the flow in-line and staggered arrangements with many rows and plotted them in the form $E u / K_{1}$ vs $R e_{D}$, where $K_{1}$ is a parameter accounting for geometry. They fitted these plots by inverse power series relationships and recommended several correlations depending on the value of $\mathcal{S}_{\mathcal{L}}$ and on the Reynolds number range. They also fitted and recommended correlations for the correction factors for the pressure drop with small number of rows. Khan ${ }^{14}$ combined all the recommended correlations for pressure drop and their correction factors separately and developed single correlations for the friction factors and correction factors for each arrangement. These correlations can be used for any pitch and Reynolds number in the laminar flow range. They are

$$
f= \begin{cases}K_{1}\left[0.233+45.78 /\left(\mathcal{S}_{T}-1\right)^{1.1} R e_{D}\right] & \text { In-line arrays } \\
K_{1}\left[378.6 / \mathcal{S}_{T}^{13.1 / \mathcal{S}_{T}}\right] / \operatorname{Re}_{D}^{0.68 / \mathcal{S}_{T}^{1.29}} & \text { Staggered arrays }\end{cases}
$$

where $K_{1}$ is a correction factor depending upon the flow geometry and arrangement of the pins. It is given by

$$
K_{1}= \begin{cases}1.009\left[\left(\mathcal{S}_{T}-1\right) /\left(\mathcal{S}_{L}-1\right)\right]^{1.09 / R e_{D}^{0.0553}} & \text { In-line arrays } \\
1.175\left(\mathcal{S}_{L} / \mathcal{S}_{T} R e_{D}^{0.3124}\right)+0.5 R e_{D}^{0.0807} & \text { Staggered arrays }\end{cases}
$$

\section{Case Studies and Discussion}

The dimensions given in Table 1 are used as the default case to determine the thermal and hydraulic resistances for both in-line and staggered pin-fin heat sinks. The air properties are evaluated at the ambient temperature. The results obtained for both in-line and staggered arrangements are shown in Table 2. It is important to note that for spreading resistance, two different models were used, but the approximate model of Song et al. ${ }^{17}$ give values $24 \%$ higher than the full model of Yovanovich et al. ${ }^{16}$ The reason may be due to the fact that the Song et al. ${ }^{17}$ model includes the material resistance $R_{m}$ in itself. However, if the material resistance $R_{m}$ is added to the full model of Yovanovich et al. ${ }^{16}$ then the difference decreases to $2 \%$. Table 2 shows that the in-line arrangement gives higher heat-sink resistance and lower pressure drop than the staggered arrangement. As a result, the average heat transfer coefficient and the fan-power requirement will be lower for the in-line arrangement. The largest thermal resistances and consequently the controlling resistances in the path between the source and the sink are usually the fin and film resistances. In the following sections, it is shown that, for a

Table 1 Dimensions used to determine performance of heat sinks

\begin{tabular}{lcc}
\hline \hline Quantity & Unit & Dimension \\
\hline Footprint, $L \times W$ & $\mathrm{~mm}^{2}$ & $25.4 \times 25.4$ \\
Source dimensions, $l \times w$ & $\mathrm{~mm}^{2}$ & $18.0 \times 18.0$ \\
Baseplate thickness $t_{b}$ & $\mathrm{~mm}$ & 2 \\
Pin diameter $D$ & $\mathrm{~mm}$ & 2 \\
Overall height of heat sink $H_{o}$ & $\mathrm{~mm}$ & 12 \\
Number of pins (in-line), $N_{T} \times N_{L}$ & & $7 \times 7$ \\
Number of pins (staggered), $N_{T} \times N_{L}$ & & $8 \times 7$ \\
Approach velocity $U_{\text {app }}$ & $\mathrm{m} / \mathrm{s}$ & 3 \\
Thermal conductivity of solid $k$ & $\mathrm{~W} / \mathrm{m} \cdot \mathrm{K}$ & 237 \\
Thermal conductivity of fluid $k_{f}$ & $\mathrm{~W} / \mathrm{m} \cdot \mathrm{K}$ & 0.026 \\
Thermal contact conductance $h_{c}$ & $\mathrm{~W} / \mathrm{m}^{2} \cdot \mathrm{K}$ & $10^{4}$ \\
Thermal joint resistance $R_{j}$ & $\mathrm{~K} / \mathrm{W}$ & 0.004 \\
Density of fluid $\rho$ & $\mathrm{kg} / \mathrm{m}^{3}$ & 1.1614 \\
Specific heat of fluid $c_{p}$ & $\mathrm{~J} / \mathrm{kg} \cdot \mathrm{K}$ & 1,007 \\
Kinematic viscosity $v$ & $\mathrm{~m}{ }^{2} / \mathrm{s}$ & $1.58 \times 10^{-5}$ \\
Prandtl number $P r$ & & 0.71 \\
Heat load $Q$ & $\mathrm{~W}$ & 10 \\
Ambient temperature $T_{a}$ & ${ }^{\circ} \mathrm{C}$ & 27 \\
\hline \hline
\end{tabular}

Table 2 Thermal and hydraulic resistances for in-line and staggered heat sinks

\begin{tabular}{lcc}
\hline \hline & \multicolumn{2}{c}{ Fin arrangement } \\
\cline { 2 - 3 } Parameter & in-line & Staggered \\
\hline & Thermal resistance & $(K / W)$ \\
Thermal joint & 0.004 & 0.004 \\
Spreading (Song model) & 0.046 & 0.042 \\
Spreading (Yovanovich model) & 0.034 & 0.033 \\
Material & 0.013 & 0.013 \\
Source side (Song model) & 0.050 & 0.046 \\
Source side (Yovanovich model) & 0.051 & 0.050 \\
Contact & 0.650 & 0.500 \\
Fin & 65.88 & 46.64 \\
Film & 42.64 & 47.16 \\
Fluid side & 1.320 & 0.720 \\
Total thermal resistance & 1.366 & 0.771 \\
& Pressure drop $(P a)$ & 35.32 \\
Contraction & 23.20 & 191.70 \\
Core friction & 55.12 & 5.63 \\
Expansion & 0.12 & 232.65 \\
Total pressure drop & 78.44 & \\
\hline
\end{tabular}




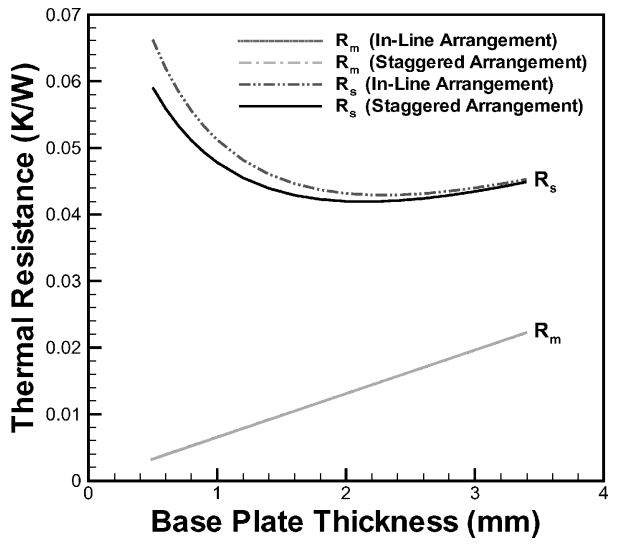

Fig. 8 Effect of $t_{b}$ on $R_{m}$ and $R_{s}$ for both in-line and staggered arrangements.

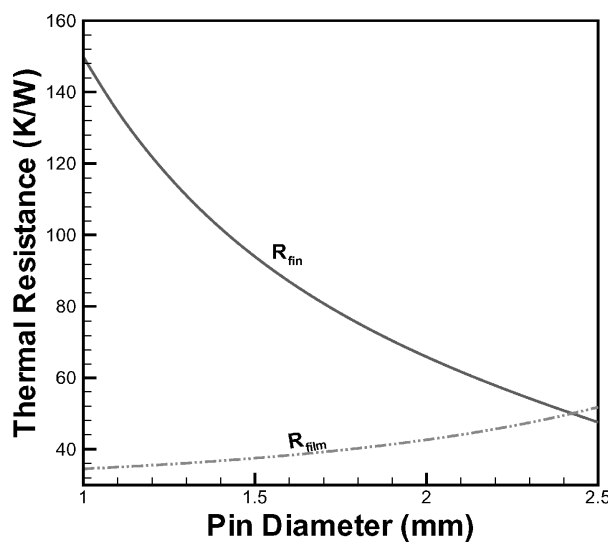

Fig. 9 Effect of $D$ on thermal resistances.

given size and heat load, the overall performance of a pin-fin heat sink depends on a number of parameters, and the thermal resistance decreases whereas pressure drop increases with an increase in approach velocity, pin diameter, and pin density.

\section{A. Effect of Baseplate Thickness $t_{b}$ on Thermal Resistance}

The thermal resistance of a heat sink is a combination of different resistances (Fig. 3). There is no effect of $t_{b}$ on the thermal joint resistance $R_{j}$, contact resistance $R_{c}$, fin resistance $R_{\text {fin }}$, and film resistance $R_{\text {film }}$. However, material resistance $R_{m}$ and spreading resistance $R_{s}$ change with $t_{b}$. This effect is shown in Fig. 8 for both arrangements. No effect of arrangement could be found on $R_{m}$. However, $R_{s}$ shows effects of arrangement for smaller $t_{b}$, and this effect diminishes as $t_{b}$ increases. For smaller $t_{b}$, the spreading resistance for the in-line arrangement is higher than the staggered arrangement, and this difference also diminishes with the increase in $t_{b}$. An optimum $t_{b}$ exists for $R_{s}$ in both arrangements.

\section{B. Effect of Pin Diameter $D$ on Thermal Resistance}

The effect of pin diameter $D$ on thermal resistances is investigated in this section for an in-line arrangement. As expected, the thermal joint $R_{j}$, the material $R_{m}$, and the thermal spreading $R_{s}$ resistances are found to be independent of pin diameter. However, other resistances show variations for different pin diameters. The variatation in $R_{c}$ with respect to pin diameter is very small compared to $R_{\text {fin }}$ and $R_{\text {film }}$, and it decreases with the increase in pin diameter. The variation of $R_{\text {fin }}$ and $R_{\text {film }}$ with $D$ is shown in Fig. 9. $R_{\text {fin }}$ decreases and $R_{\text {film }}$ increases with the increase in $D$. This is mainly because of an increase in contact and heat transfer surface areas and a decrease in the unfinned area of the baseplate with the increase in pin diameter. Because $R_{\text {fin }}$ is in series with $R_{c}$ and parallel with $R_{\text {film }}$, the total thermal resistance on the fluid side $R_{f}$ decreases with the increase in pin diameter $D$.

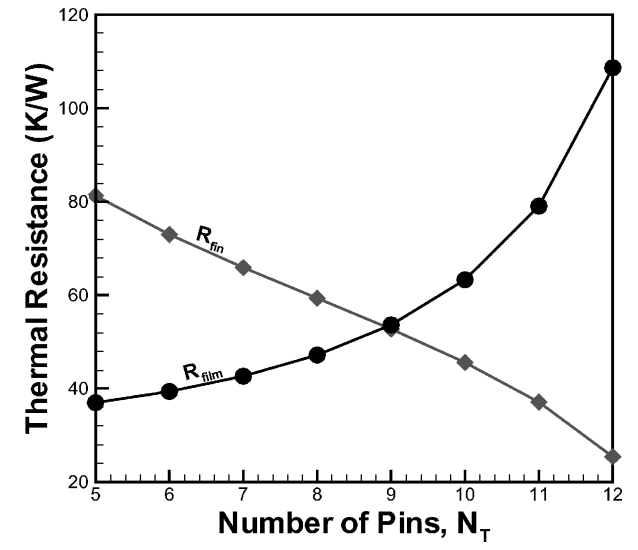

Fig. 10 Effect of pin density on thermal resistances for in-line arrangement.

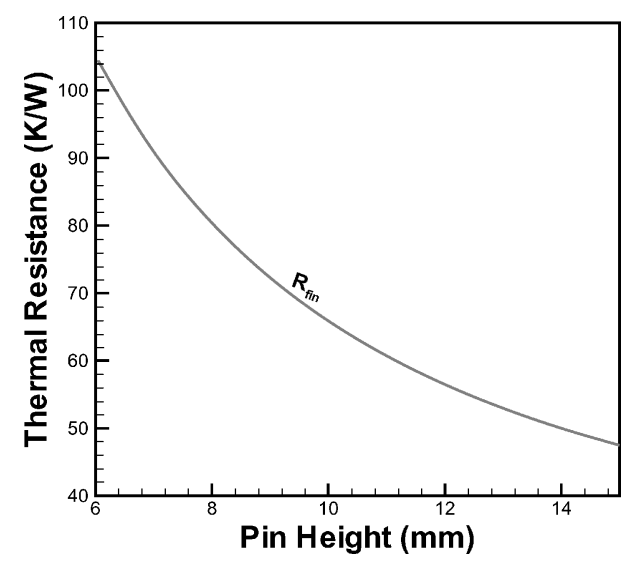

Fig. 11 Effect of pin height on thermal resistances for in-line arrangement.

\section{Effect of Pin Density $\boldsymbol{N}$ on Thermal Resistance}

The effect of pin density on $R_{\text {fin }}$ and $R_{\text {film }}$, for an in-line arrangement, is shown in Fig. 10. Like pin diameter, pin density also has no appreciable effect on $R_{j}, R_{m}$, and $R_{s}$. The contact resistance $R_{c}$ decreases with pin density because of an increase in contact area, but this change is again very small compared to fin and film resistances. With the increase in pin density, heat transfer surface area increases and as a result the fin resistance decreases, whereas film resistance increases with the pin density because of a decrease in unfinned surface area.

\section{Effect of Pin Height $\boldsymbol{H}$ on Thermal Resistance}

$R_{j}, R_{m}, R_{s}, R_{c}$, and $R_{\text {film }}$ do not show any change with an increase or decrease in pin height. However, the fin resistance $R_{\text {fin }}$ and hence the total thermal resistance on the fluid side $R_{f}$ decrease with the increase in pin height. This effect of height on fin resistance is shown in Fig. 11 for an in-line arrangement. This variation is mainly due to an increase in fin surface area.

\section{E. Effect of Approach Velocity $\boldsymbol{U}_{\text {app }}$ on Overall Performance}

The thermal resistance and the total pressure drop for the heat sink assembly are plotted as function of the approach velocity in Fig. 12 for both in-line and staggered arrangements. $R_{\mathrm{hs}}$ decreases and $\Delta P$ increases with the increase in approach velocity in both arrangements. It is not possible to get the highest performance (thermal or hydraulic) at the same time. If we want highest thermal performance (minimum $R_{\mathrm{hs}}$ ), then we have to pay with higher pressure drop (in terms of pumping power), and if we are looking for minimum pressure drop, then we have to pay with higher $R_{\mathrm{hs}}$. In an optimal heat sink, there is a trade-off (point of intersection) between these two resistances. It can be seen easily in Fig. 12 that the staggered arrangement has lower $R_{\mathrm{hs}}$ but requires higher $\Delta P$. However, the point of 


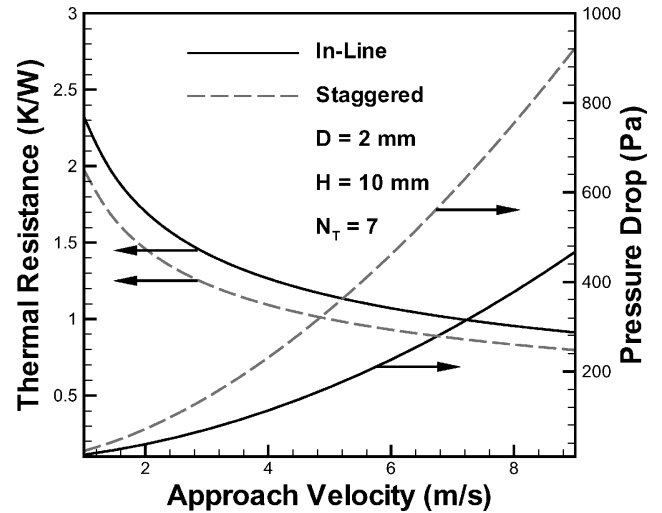

Fig. 12 Performance of PFHS as function of approach velocity.

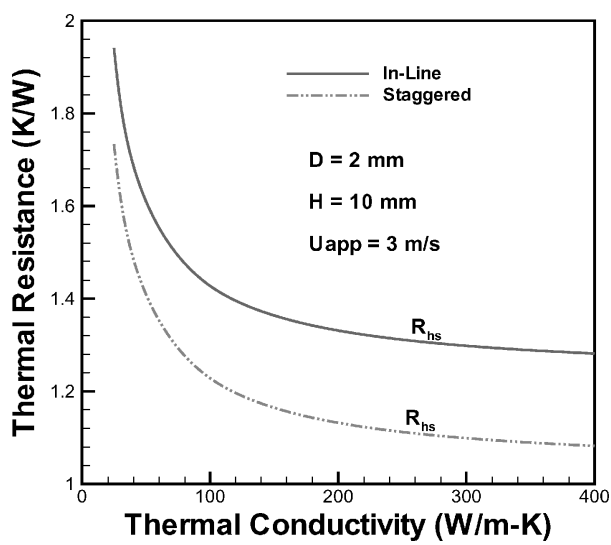

Fig. 13 Performance of PFHS as function of thermal conductivity.

intersection of $R_{\mathrm{hs}}$ and $\Delta P$ gives a lower approach velocity for a staggered arrangement. It shows that lower approach velocities give better overall performance in staggered arrangements.

\section{F. Effect of Thermal Conductivity $k$ of Material on Thermal Performance}

The same dimensions of the heat sinks are used to determine the thermal performance of the heat sinks for a range of thermal conductivities, which includes a variety of materials from plastic composites $(k=25 \mathrm{~W} / \mathrm{m} \cdot \mathrm{K})$ to copper $(k=400 \mathrm{~W} / \mathrm{m} \cdot \mathrm{K})$. Results for both arrangements, presented in Fig. 13, show that the thermal performance of a heat sink increases with an increase in thermal conductivity.

As expected, the thermal performance of in-line pin-fin heat sinks is lower than the staggered pin-fin heat sinks for the same material. The difference in thermal performance between two arrangements is around $11 \%$ for $k=25 \mathrm{~W} / \mathrm{m} \cdot \mathrm{K}$, which increases to $16 \%$ for $k=400 \mathrm{~W} / \mathrm{m} \cdot \mathrm{K}$. However, the difference in thermal performance of aluminum $k=237 \mathrm{~W} / \mathrm{m} \cdot \mathrm{K}$ and copper $k=400 \mathrm{~W} / \mathrm{m} \cdot \mathrm{K}$ is around $1.5 \%$ for the same arrangement. So, when the cost and weight are the main constraints, aluminum can be considered as the best material for any type of arrangement.

\section{Summary}

Energy balances and thermal-circuit concepts are employed to develop mathematical models for thermal and hydraulic resistances of the heat sink. The analysis of in-line and staggered pin-fin heat sinks is performed using parametric variation of both resistances. The thermal resistance decreases whereas pressure drop increases with pin diameter, pin density, and approach velocity. The effects of thermal joint, spreading, and contact resistance on the thermal performance are examined in detail. The effects of thermal conduc- tivity on thermal resistance are also examined in both arrangements. The average heat transfer coefficient and the pressure drop are lower for the in-line pin-fin heat sink. Smaller diameter pin-fins and low approach velocities give better performance for the staggered arrangement than for the in-line arrangement, and aluminum can be considered as the best material for any type of arrangement. The overall performance of the staggered arrangement is better than the in-line arrangement.

\section{Acknowledgments}

The authors gratefully acknowledge the financial support of Natural Sciences and Engineering Research Council of Canada and the Center for Microelectronics Assembly and Packaging.

\section{References}

${ }^{1}$ Wirtz, R. A., Sohal, R., and Wang, H., "Thermal Performance of Pin-Fin Fan-Sink Assemblies," Journal of Electronic Packaging, Vol. 119, March 1997, pp. 26-31.

${ }^{2}$ Jonsson, H., and Bjorn, P., "Experimental Comparison of Different Heat Sink Designs for Cooling of Electronics," American Society of Mechanical Engineers, Heat Transfer Division, HTD, Vol. 329, No. 7, Association of Mechanical Engineers, New York, 1996, pp. 27-34.

${ }^{3}$ Babus'Haq, R. F., Akintunde, K., and Probert, S. D., "Thermal Performance of a Pin-Fin Assembly," International Journal of Heat and Fluid Flow, Vol. 16, No. 1, 1995, pp. 50-55.

${ }^{4}$ Azar, K., and Mandrone, C. D., "Effect of Pin Fin Density of the Thermal Performance of Unshrouded Pin Fin Heat Sinks," ASME Journal of Electronic Packaging, Vol. 116, No. 4, 1994, pp. 306-309.

${ }^{5}$ Minakami, K., and Iwasaki, H., "Heat-Transfer Characteristics of Pin-Fins with In-Line Arrangement," Heat Transfer-Japanese Research, Vol. 23, No. 3, 1994, pp. 213-228.

${ }^{6}$ Tahat, M. A., Babus'Haq, R. F., and Probert, S. D., "Forced Steady-State Convections from Pin Fin Arrays," Applied Energy, Vol. 48, No. 4, 1994, pp. 335-351.

${ }^{7}$ Dvinsky, A., Bar-Cohen, A., and Strelets, M., "Thermofluid Analysis of Staggered and In-line Pin Fin Heat Sinks," The Seventh Inter-Society Conference on Thermal Phenomena, Vol. 1, 2000, pp. 157-164.

${ }^{8}$ Jung, H. H., and Maveety, J. G., "Pin Fin Heat Sink Modeling and Characterization," Sixteenth IEEE Semi-Therm Symposium, IEEE Publications, Piscataway, NJ, March 2000, pp. 260-265.

${ }^{9}$ You, H. I., and Chang, C. H., "Numerical Prediction of Heat Transfer Coefficient for a Pin-Fin Channel Flow," Journal of Heat Transfer, Vol. 119, No. 4, 1997, pp. 840-843.

${ }^{10}$ Yovanovich, M. M., "Thermal Contact Correlations," Spacecraft Radiative Transfer and Temperature Control, edited by T. E. Horton, Progress in Aeronautics and Aerodynamics, Vol. 83, AIAA, New York, 1982, pp. 83-95.

${ }^{11}$ Yovanovich, M. M., "New Contact and Gap Conductance Correlations for Conforming Rough Surfaces," AIAA Paper 81-1164, June 1981.

${ }^{12}$ Savija, I., Culham, J. R., Yovanovich, M. M., and Marotta, E. E., "Review of Thermal Conductance Models for Joints Incorporating Enhancement Materials," Journal of Thermophysics and Heat Transfer, Vol. 17, No. 1, 2003, pp. 43-52.

${ }^{13}$ Bahrami, M., Culham, J. R., and Yovanovich, M. M., "Thermal Resistances of Gaseous Gap for Conforming Rough Contacts," AIAA Paper 2004-0821, Jan. 2004.

${ }^{14}$ Yovanovich, M. M., Culham, J. R., and Teertstra, P., "Calculating Interface Resistances," Electronics Cooling, Vol. 3, No. 2, 1997, pp. 24-29.

${ }^{15}$ Khan, W. A., "Modeling of Fluid Flow and Heat Transfer for Optimization of Pin-Fin Heat Sinks," Ph.D. Dissertation, Dept. of Mechanical Engineering, Univ. of Waterloo, Canada, July 2004.

${ }^{16}$ Yovanovich, M. M., Muzychka, Y. S., and Culham, J. R., "Spreading Resistance of Isoflux Rectangles and Strips on Compound Flux Channels," Journal of Thermophysics and Heat Transfer, Vol. 13, No. 4, 1999, pp. 495-500.

${ }^{17}$ Song, S., Lee, S., and Au, V., "Closed-Form Equation for Thermal Constriction/Spreading resistances with Variable Resistance Boundary Condition," Proceedings of the Technical Conference, International Packaging Society, Wheaton, IL, 1994, pp. 111-121.

${ }^{18}$ Kays, W. M., "Loss Coefficients for Abrupt Changes in Flow Cross Section with Low Reynolds Number Flow in Single and Multiple Tube Systems," Transactions of ASME, Vol. 72, Nov. 1950, pp. 1067-1074.

${ }^{19}$ Žukauskas, A., and Ulinskas, R., "Single-Phase Fluid Flow: Banks of Plain and Finned Tubes," Heat Exchanger Design Handbook, Hemisphere Publishing, Washington, DC, 1983, Chap. 2.2.4. 